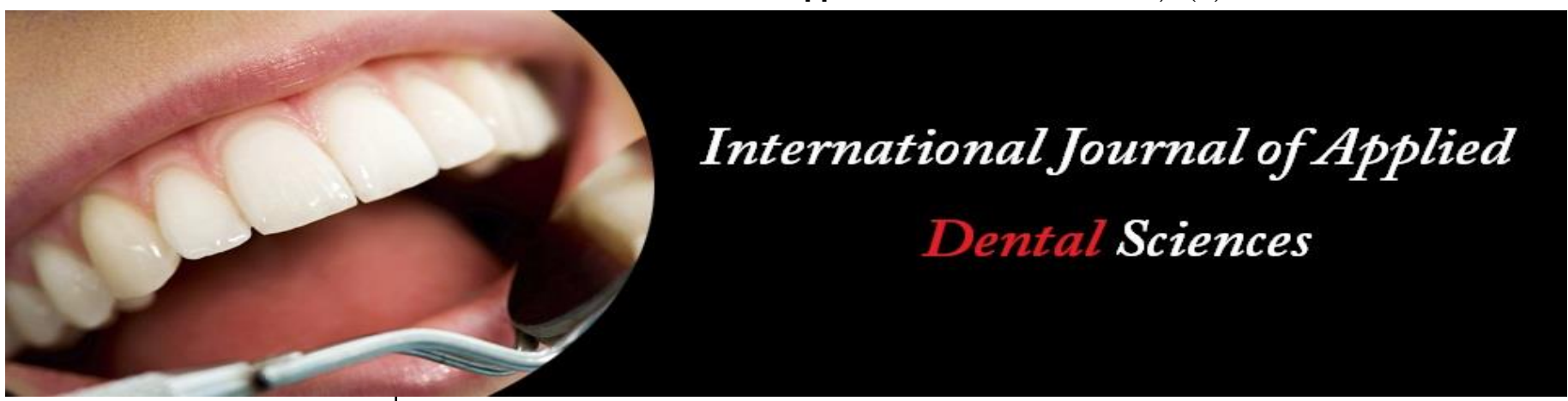

ISSN Print: 2394-7489

ISSN Online: 2394-7497

IJADS 2021; 7(3): 77-81

(C) 2021 IJADS

www.oraljournal.com

Received: 04-05-2021

Accepted: 06-06-2021

Vanascheck Villanueva Perez

Master in Sciences Student,

Universidad Autonoma de

Nuevo Leon, Facultad de

Odontologia, Monterrey, Nuevo

Leon, CP 64460, Mexico

Maria Concepcion Treviño-

Tijerina

Profesor, Universidad Autonoma

de Nuevo Leon, Facultad de

Odontologia, Monterrey, Nuevo

Leon, CP 64460, Mexico

Juana Nelly Leal-Camarillo

Profesor, Universidad Autonoma de Nuevo Leon, Facultad de

Odontologia, Monterrey, Nuevo

Leon, CP 64460, Mexico

Lizeth Edith Quintanilla

Rodriguez

Profesor, Universidad Autonoma

de Nuevo Leon, Facultad de

Odontologia, Monterrey, Nuevo

Leon, CP 64460, Mexico

Sara Saenz Rangel

Profesor, Universidad Autonoma de Nuevo Leon, Facultad de

Odontologia, Monterrey, Nuevo

Leon, CP 64460, Mexico

Rosa Isela Sanchez-Najera

Profesor, Universidad Autonoma

de Nuevo Leon, Facultad de

Odontologia, Monterrey, Nuevo

Leon, CP 64460, Mexico

Juan Manuel Solis-Soto

Profesor, Universidad Autonoma

de Nuevo Leon, Facultad de

Odontologia, Monterrey, Nuevo

Leon, CP 64460, Mexico

Corresponding Author:

Vanascheck Villanueva Perez

Master in Sciences Student,

Universidad Autonoma de

Nuevo Leon, Facultad de

Odontologia, Monterrey, Nuevo

Leon, CP 64460, Mexico

\section{Candida albicans, from endodontic point of view}

\author{
Vanascheck Villanueva Perez, Maria Concepcion Treviño-Tijerina, Juana \\ Nelly Leal-Camarillo, Lizeth Edith Quintanilla Rodriguez, Sara Saenz \\ Rangel, Rosa Isela Sanchez-Najera and Juan Manuel Solis-Soto
}

DOI: $\underline{\text { https://doi.org/10.22271/oral.2021.v7.i3b.1282 }}$

\section{Abstract}

Introduction: Candida albicans is a ubiquitous commensal organism that commonly colonizes the oral mucosa. In fact, up to $80 \%$ of the general population are carriers.

Objective: To analyze the literature about $C$. albicans, its epidemiology, diagnosis, clinical manifestations, antimicrobial resistance and treatment in relation to endodontics.

Methodology: Using the keywords Candida albicans in conjunction with epidemiology, diagnosis, clinical manifestations, antimicrobial resistance and treatment, the main public databases were searched, with emphasis on the last 5 years. It was evaluated with the PRISMA and AMSTAR-2 guidelines.

Results: C. albicans is the fungus most frequently isolated in root canal infections, it binds to the dentin to form biofilms within the dentin tubules. C. albicans can be detected by different diagnostic methods, the most used is cultivation. This microorganism is increasingly found in the oral cavity, it is responsible for endodontic failure, its biofilms are inherently resistant to antifungal drugs, the host's immune system, environmental stresses and biomechanical treatment. The most favourable method to eliminate is using Qmi X irritant and Endo Vac as a suction system, together with chemo mechanical debridement. Conclusions: $C$. albicans is a pathogen which has been presenting itself more frequently in the oral cavity, in the endodontic area, it is the fungus that is most frequently found in the root canals, either due to primary or secondary infection.

Keywords: Candida albicans, epidemiology, diagnosis, clinical manifestations, antimicrobial resistance, treatment

\section{Introduction}

C. albicans is by far the main causative agent of oral candidiasis and accounts for up to $95 \%$ of cases. Although considered a pathogen, $C$. albicans is a ubiquitous commensal organism that commonly colonizes the oral mucosa. In fact, up to $80 \%$ of the general population are carriers [1]. In the oral cavity, Candida-associated infections are referred to as oral candidosis, of which there are four main clinical presentations: chronic and acute erythematous, pseudomembranous and chronic hyperplastic candidosis ${ }^{[2]}$. An important consideration in endodontic treatment is the elimination of microorganisms, including fungi. Candida albicans (CA) plays an important role in endodontic treatment failure as the most important fungus isolated from the root canal system ${ }^{[3]}$. C. albicans frequently resides in the oral cavity as a biofilm-forming microorganism. When considering root canal infections, pathogenic yeasts have also been isolated from teeth associated with primary apical periodontitis and post-treatment disease ${ }^{[4]}$. C. albicans is the species most frequently isolated in endodontic infections, its prevalence in persistent infections is higher than in primary infections ${ }^{[5]}$. Root canal treatment (RCT) is the treatment of choice for these endodontic infections. RCT aims to: remove microorganisms from the root canal system to a level that promotes healing of periarticular tissues and provide a three-dimensional tight seal to prevent reinfection. During RCT, different hand and rotary instruments are used to mechanically debride the biofilm on the root canal walls ${ }^{[6]}$. In case of a failed endodontic procedure, specific fungal species grow as a result of intercommunication between certain bacteria due to changes in intracanal oxygen pressure and environment ${ }^{[7]}$.

Failure in endodontic treatment is caused by bacterial colonization of the root canal system and periarticular tissues. 
The literature mentions that Candida albicans may be one of the causes, along with other bacteria, of endodontic treatment failures because it is identified in cultivation samples taken from root canals with primary or secondary infection and its various mechanisms of resistance to some antibiotics. The aim of this article is to analyze the literature about Candida albicans, its epidemiology, diagnosis, clinical manifestations, antimicrobial resistance and treatment in relation to endodontics.

\section{Materials and Methods}

Articles on the subject published through the PubMed, SCOPUS and Google Scholar databases were analyzed, with emphasis on the last 5 years. The quality of the articles was evaluated using PRISMA guidelines, i.e., identification, review, choice and inclusion. The quality of the reviews was assessed using the measurement tool for evaluating systematic reviews (AMSTAR-2). The search was performed using Boolean logical operators AND, OR and NOT. It was realized with the words Candida albicans in conjunction with epidemiology, diagnosis, clinical manifestations, antimicrobial resistance and treatment. The keywords were used individually, as well as each of them related to each other.

\section{Results and Discussion 3.1 Epidemiology}

The main supply of $C$. albicans in the body is found in the gastrointestinal tract and the development of infections occurs due to dysbiosis of the residential microbiota, immune dysfunction and damage to the muco-intestinal barrier ${ }^{[8]}$. A small number of Candida species are part of the normal microbial flora of human mucosal surfaces and can give rise to opportunistic infections when host defenses are impaired. This pathogen is by far the most prevalent commensal Candida species ${ }^{[9]}$. Candida albicans is the most frequently isolated fungus in endodontic root canal infections. Although it is recognized by cells in the dental pulp and periradicular tissue that elicit immune responses, it evades host defenses and causes cell death. This fungus then binds to tooth dentin, forms biofilms and invades dentinal tubules to resist intracanal disinfectants and endodontic treatments [10]. Overall, 9,769 (6.09\%) of the 160,357 patients examined were diagnosed with oral candidiasis on the basis of clinical manifestations and laboratory tests. The ratio of females to males was 1:0.61, and females had higher overall infection rates than males in all age subgroups ${ }^{[11]}$. Patients with longterm diabetes mellitus carried $C$. albicans in their root canals more frequently when they had a primary endodontic infection. Furthermore, this presence of C. albicans seems to be related to a higher frequency of apical periodontitis [12]. The frequency of yeasts was higher in teeth with primary infections compared to teeth with persistent infections. The predominant yeast species was this microorganism ${ }^{[13]}$. Failure of endodontic treatment has been associated with the persistence of microbial flora after therapy in the root canal system, and this includes this fungus, which is resistant to conventional root canal irrigants ${ }^{[14]}$. A cross-sectional study was conducted where saliva samples were collected from 48 patients who used dentures and 43 patients (control group) who did not use dentures. Among the 91 patients, Candida spp was isolated in $40(83.3 \%)$ who used prostheses and in 23 $(53.5 \%)$ in the control group ${ }^{[15]}$.

Candida albicans is the most frequent fungus in root canals forming biofilms, regularly found in primary endodontic infections than in persistent infections, in which this yeast is resistant to irrigants and causes endodontic failure.

\subsection{Diagnosis}

CHROM agar for Candida speciation is a differential cultivation method that facilitates the isolation and identification of some clinically important species ${ }^{[16]}$. The cultures are sensitive for detecting viable Candida. At the time of the first positive blood culture, the mean Candida concentration is $1 \mathrm{CFU} / \mathrm{ml}^{[17]}$.

Biochemical profiling based on vibrational spectroscopy reflects the variability of chromosomal patterns and DNA content of clinical isolates of Candida species and can facilitate diagnosis and targeted therapy of candidiasis ${ }^{[18]}$. Restriction enzyme analysis with Mwol and BslI can be used for Candida species identification in situations where rapid identification is necessary or conventional methods are problematic ${ }^{[19]}$. The application of $C$. albicans microarrays in early studies on pathogenesis, cell biology, antifungal susceptibility and diagnostics confirmed their usefulness, and the results showed good correlations with data obtained with other techniques. These studies and those published in the near future will surely be the basis for a better understanding of the biology of this pathogen ${ }^{[20]}$.

Presumptive identification of fungal species was performed using conventional methods like colony characteristics on CHRO Magar Candida medium, germ tube production and evaluation of fungal morphology on corn meal agar. Confirmation of presumptive Candida isolates was performed by PCR-RFLP ${ }^{[21]}$. A potential for electrochemical impedance detection of Candida albicans at clinically relevant concentrations was demonstrated. The developed sensor showed high sensitivity and specificity towards Candida albicans providing rapid and accurate detection in less than 1 hour. Future work requires optimization of the sensor functionalization protocol to ensure more reliable target binding ${ }^{[22]}$. EphA2-deficient mice demonstrated reduced inflammatory responses and IL-17 signalling, resulting in severe disease. Therefore, EphA2 PRR in oral epithelial cells is key to detect $C$. albicans and induce an immune response [23]

Currently, many laboratory methods are available for the identification of this fungus; $C$. albicans is a bacterium that is well studied, its form, behavior and the media in which it develops; therefore, it can be easily identified by different diagnostic methods.

\subsection{Clinical Manifestations}

C. albicans is the most common and best studied of the Candida spp., that naturally colonizes the skin, genital and/or intestinal mucosa in up to $70 \%$ of healthy individuals ${ }^{[24]}$. The most common oral manifestation in HIV-infected subjects taking Highly Active Antiretroviral Therapy (HAART) was hyperpigmentation. Candida colonization was detected in $64 \%, 65 \%$, and $35 \%$ of HIV-infected subjects taking HAART, subjects without HAART pretreatment, and HIVnegative subjects, respectively. Interestingly, the group that had not received HAART was colonized more by nonalbicans species ${ }^{[25]}$. In pediatric AIDS patients, the sample consisted of 117 children. A dental examination assessed the prevalence of dental caries. The prevalence of oral Candida colonization was $62 \%$. Only seven children presented clinical manifestation of oral candidiasis despite their high viral load index and low CD4 count for their age ${ }^{[26]}$. This fungus can rarely cause clinically significant pneumonia in adults and 
should be considered in the differential diagnosis of suppurative granulomas in the lung ${ }^{[27]}$. Candida albicans is closely associated with the occurrence of oral diseases such as childhood caries, root caries, periodontitis, root canal infection, soft tissue infection and facial space infection ${ }^{[28]}$. Similarly, this microorganism colonizes the gastrointestinal (GI) and genitourinary tract of healthy individuals [29]. Clinical manifestations included pain $(82 \%)$, edema $(71 \%)$, limited function (39\%) and erythema (22\%) with knees $(75 \%)$ and hips (15\%) most commonly infected. Candida albicans constituted $63 \%{ }^{[30]}$. This pathogen is considered one of the most resistant fungal species, which are responsible for root canal treatment failures. The collagenolytic activity of this microorganism promotes colonization in the root canal, as it uses dentin as a source of nutrients, leading to its high virulence ${ }^{[31]}$.

Candida manifests itself in different sites of the organism, mainly in patients who are immunosuppressed and is increasingly found in the oral cavity, where in the endodontic area, it is the main fungus found in the root canal and also in endodontic failure.

\subsection{Antimicrobial Resistance}

C. albicans biofilms are inherently resistant to antifungal drugs, the host immune system, and environmental stresses. Biofilm is a major virulence factor and an important clinical challenge ${ }^{[32]}$. The plasticity of the mycelial form is a determinant of drug resistance and is also an important form during the infection stage ${ }^{[33]}$. Once a biofilm of this fungus forms on an implanted medical device, it acts as a reservoir of pathogenic cells, is highly resistant to drugs and the host immune system, and has the potential to seed disseminated bloodstream infections (candidemia) that can lead to systemic invasive tissue and organ infections ${ }^{[34]}$. This fungus can occur and transform between the spore, hyphal and mycelial stages ${ }^{[35]}$. In addition, transformation to hyphal yeast can help fungi escape macrophage phagocytosis, which increases the likelihood of invading host tissues and causing further damage ${ }^{[36]}$. A phenomenon of increasing resistance of Candida spp. to azoles has been observed for several years, one of the mechanisms of lack of sensitivity to azoles is associated with CDR1, CDR2 and MRD1 genes ${ }^{[37]}$. The role of fungi in endodontic diseases is also well documented. Persistence of virulent microorganisms and their by-products in the root canal system, or surrounding tissues, after initial endodontic treatment is the main cause of treatment failure ${ }^{[38]}$. C. albicans and C. glabrata are resistant to several agents, including calcium hydroxide $\left(\mathrm{Ca}(\mathrm{OH})_{2}\right)$, used in root canal therapy ${ }^{[39]}$.

C. albicans is a fungus which is difficult to eradicate, due to its resistance mechanism against different antibiotics, the immune system and biomechanical endodontic treatment. The literature mentions that when it forms its biofilm, it becomes a clinical challenge, because it serves as a reservoir for other pathogens.

\subsection{Treatment}

Several treatments have been used to eliminate Candida, among them, $\mathrm{NaOCl}$ and EDTA showed a measurable antimicrobial effect, even in the presence of dentin powder, which may be promising in the reduction of $C$. albicans in root canal therapy ${ }^{[40]}$. Also, the association of $2 \%$ chlorhexidine followed by ozone gas for 24 seconds promoted the complete elimination of Candida albicans and Enterococcus faecalis ${ }^{[41]}$.
A $0.0156 \%$ concentration of alexidine may be a good alternative to chlorhexidine as an irrigation solution in endodontic treatment when used for one minute against $E$. faecalis and $C$. albicans ${ }^{[42]}$. Also, probiotic organisms of Lactobacillus and Bifidobacterium species are suggested to be effective in preventing the growth of E. faecalis and $C$. albicans in vitro ${ }^{[43]}$. This microorganism can only be completely inhibited by direct contact with a saturated aqueous calcium hydroxide solution after 48 hours of exposure ${ }^{[44]}$.

The antibacterial photodynamic therapy and calcium hydroxide therapy showed the same antimicrobial efficacy on E. faecalis and C. albicans ${ }^{[45]}$.

QmiX, a root canal irrigation mixture of ethylenediamine tetraacetic acid (EDTA), chlorhexidine (CHX) and surfactant, showed inhibitory effects against Enterococcus faecalis and Candida albicans, better that Guava leaf extract, aloevera extract, $2.5 \%$ sodium hypochlorite and $2 \%$ chlorhexidine ${ }^{[46]}$.

The EndoVac irrigation/aspiration system associated with chemomechanical debridement was the most effective therapeutic protocol for reducing intra-canal levels of $C$. albicans ${ }^{[47]}$.

AH 26 exhibited strong activity against this pathogen with the minimum inhibitory concentration of $12.5 \mathrm{mg} . \mathrm{ml}^{[48]}$.

In order to eliminate $C$. albicans, the literature mentions that if it comes in direct contact with calcium hydroxide, it can be completely inhibited after 48 hours. It mentions that the most favorable irrigant to eliminate it was QmiX, and EndoVac as a suction system together with chemomechanical debridement was the most effective protocol to eliminate $C$. albicans.

\section{Conclusions}

C. albicans is a pathogen that primarily affects the skin and gastrointestinal tract. However, it has been increasingly found in the oral cavity, for example, in association with endodontic failures. Its diagnosis is mainly by cultivation and, due to its resistance to drugs, biomechanical treatment and biofilm formation, chemomechanical therapy is necessary for its intracanal elimination. The literature mentions that the most effective method to suppress this fungus is by using the QmiX irrigant and the Endo Vac as a suction system.

\section{References}

1. Vila T, Sultan AS, Montelongo-Jauregui D, Jabra-Rizk MA. Oral Candidiasis: A Disease of Opportunity. J Fungi (Basel) 2020;6(1):15.

2. Patil S, Rao RS, Majumdar B, Anil S. Clinical appearance of oral Candida infection and therapeutic strategies. Frontal microbiol 2015;(6):1-10.

3. Ashraf H, Samiee M, Eslami G, Ghodse Hosseini MR. Presence of Candida albicans in Root Canal System of Teeth Requiring Endodontic Retreatment with and without Periapical Lesions. Iran Endod J 2007;2(1):2428.

4. Siqueira JF Jr, Rôças IN. Analysis based on the polymerase chain reaction of microorganisms associated with a failed endodontic treatment. Oral Surg Oral Med Oral Pathol Oral Radiol Endod 2004;97(1):85-94.

5. Persoon IF, Crielaard W, Özok AR. Prevalence and nature of fungi in root canal infections: a systematic review and meta-analysis. Int Endod J 2017;50(11):10551066.

6. Taha NA, Ozawa T, Messer HH. Comparison of three techniques for the preparation of oval root canals. J Endod 2010;36(3):532-535. 
7. Kangarlou A, Sofiabadi S, Yadegari Z, Asgary S. Antifungal effect of calcium-enriched cement mix against Candida albicans. Iran Endod J 2009;4(3):101-105.

8. Talapko J, Juzbašić M, Matijević T, Pustijanac E, Bekić S, Kotris I. Candida albicans-The Virulence Factors and Clinical Manifestations of Infection. J Fungi (Basel) 2021;7(2):79.

9. McManus BA, Coleman DC. Molecular epidemiology, phylogeny and evolution of Candida albicans. Infect Genet Evol 2014;21:166-178.

10. Yoo YJ, Kim AR, Perinpanayagam H, Han SH, Kum KY. Candida albicans Virulence Factors and Pathogenicity for Endodontic Infections. Microorganisms 2020;8(9):1300.

11. Hu L, He C, Zhao $C$, Chen $X$, Hua H, Yan Z. Characterization of oral candidiasis and the Candida species profile in patients with oral mucosal diseases. Microb Pathog 2019;134:103575.

12. De la Torre-Luna R, Domínguez-Pérez RA, GuillénNepita AL, Ayala-Herrera JL, Martínez-Martínez RE, Romero-Ayala ME, et al. Prevalence of Candida albicans in primary endodontic infections associated with a higher frequency of apical periodontitis in type two diabetes mellitus patients. Eur J Clin Microbiol Infect Dis. 2020;39(1):131-138.

13. Bernal-Treviño A, González-Amaro AM, Méndez González V, Pozos-Guillen A. Frequency of Candida in root canals of teeth with primary and persistent endodontic infections. Rev Iberoam Micol 2018;35(2):78-82.

14. Kumar J, Sharma R, Sharma M, Prabhavathi V, Paul J, Chowdary CD. Presence of Candida albicans in Root Canals of Teeth with Apical Periodontitis and Evaluation of their Possible Role in Failure of Endodontic Treatment. J Int Oral Health 2015;7(2):42-5.

15. Bianchi CM, Bianchi HA, Tadano T, Paula CR, Hoffmann-Santos HD, Leite DP Jr et al. Factors related to oral candidiasis in elderly users and non-users of removable dental prostheses. Rev Inst Med Trop Sao Paulo 2016;58:17.

16. Sharma U, Patel K, Shah V, Sinha S, Rathore VPS. Isolation and Speciation of Candida in Type II Diabetic Patients using CHROM Agar: A Microbial Study. J Clin Diagn Res 2017;11(8):DC09-DC11.

17. Clancy CJ, Nguyen $\mathrm{MH}$. Diagnosing Invasive Candidiasis. J Clin Microbiol 2018;56(5):e01909-17.

18. Potocki L, Depciuch J, Kuna E, Worek M, Lewinska A, Wnuk M. FTIR and Raman Spectroscopy-Based Biochemical Profiling Reflects Genomic Diversity of Clinical Candida Isolates That May Be Useful for Diagnosis and Targeted Therapy of Candidiasis. Int $\mathbf{J}$ Mol Sci 2019;20(4):988.

19. Yiş R, Doluca M. Identification of Candida species by restriction enzyme analysis. Turk J Med Sci 2018;48(5):1058-1067.

20. Garaizar J, Brena S, Bikandi J, Rementeria A, Pontón J. Use of DNA microarray technology and gene expression profiles to investigate the pathogenesis, cell biology, antifungal susceptibility and diagnosis of Candida albicans. FEMS Yeast Res 2006;6(7):987-98.

21. Hamzehee S, Kalantar-Neyestanaki D, Mohammadi MA, Nasibi S, Mousavi SAA. Identification of Candida spp. Isolated from oral mucosa in patients with leukemias and lymphomas in Iran. Iran J Microbiol 2019;11(2):114-119.

22. Kwasny D, Tehrani SE, Almeida C, Schjødt I, Dimaki
M, Svendsen WE. Direct Detection of Candida albicans with a Membrane Based Electrochemical Impedance Spectroscopy Sensor. Sensors (Basel) 2018;18(7):2214.

23. Swidergall M, Solis NV, Lionakis MS, Filler SG. EphA2 is an epithelial cell pattern recognition receptor for fungal $\beta$-glucans. Nat Microbiol 2018;3(1):53-61.

24. Kashem SW, Kaplan DH. Skin Immunity to Candida albicans. Trends Immunol. 2016;37(7):440-450.

25. Lam-Ubol A, Rungsiyanont S, Vacharotayangul P, Sappayatosok K, Chankanka O. Oral manifestations, salivary flow rates and Candida species in Thai HIVinfected patients. J Clin Exp Dent 2019;11(2):e138-e145.

26. Domaneschi C, Massarente DB, de Freitas RS, de Sousa Marques HH, Paula CR, Migliari DA, Antunes JL. Oral colonization by Candida species in AIDS pediatric patients. Oral Dis 2011;17(4):393-398.

27. Dermawan JKT, Ghosh S, Keating MK, Gopalakrishna KV, Mukhopadhyay S. Candida pneumonia with severe clinical course, recovery with antifungal therapy and unusual pathologic findings: A case report. Medicine (Baltimore) 2018;97(2):e9650.

28. Krom BP, Kidwai S, Ten Cate JM. Candida and other fungal species: forgotten players of healthy oral microbiota. J Dent Res 2014;93(5):445-51.

29. Du H, Bing J, Hu T, Ennis CL, Nobile CJ, Huang G. Candida auris: Epidemiology, biology, antifungal resistance, and virulence. PLoS Pathog 2020;16(10):e1008921.

30. Gamaletsou MN, Rammaert B, Bueno MA, Sipsas NV, Moriyama B, Kontoyiannis DP, et al. Candida Arthritis: Analysis of 112 Pediatric and Adult Cases. Open Forum Infect Dis. 2015;3(1):ofv207.

31. Yadav P, Chaudhary S, Saxena RK, Talwar S, Yadav S. Evaluation of Antimicrobial and Antifungal efficacy of Chitosan as endodontic irrigant against Enterococcus faecalis and Candida albicans Biofilm formed on tooth substrate. J Clin Exp Dent 2017;9(3):e361-e367.

32. Guo D, Yue H, Wei Y, Huang G. [Genetic regulatory mechanisms of Candida albicans biofilm formation]. Sheng Wu Gong Cheng Xue Bao 2017;33(9):1567-1581. Chinese.

33. Thomson DD, Wehmeier S, Byfield FJ. Contact-induced apical asymmetry drives the thigmotropic responses of Candida albicans hyphae. Cell Microbiol 2015;1(3):342354.

34. Gulati M, Nobile CJ. Candida albicans biofilms: development, regulation, and molecular mechanisms. Microbes Infect 2016;18(5):310-21.

35. Deng L, Xue J, Jiang L, Zou L, Li W. [Research progress on interactions between Candida albicans and common oral pathogens]. Hua Xi Kou Qiang Yi Xue Za Zhi. 2019;37(6):671-676.

36. Chen H, Zhou X, Ren B, Cheng L. The regulation of hyphae growth in Candida albicans. Virulence. 2020;11(1):337-348.

37. Gołąbek K, Strzelczyk JK, Owczarek A, Cuber P, ŚlempMigiel A, Wiczkowski A. Selected mechanisms of molecular resistance of Candida albicans to azole drugs. Acta Biochim Pol 2015;62(2):247-5.

38. Bhardwaj A, Bhardwaj A, Rao N. Evaluation of antifungal activity of white-colored mineral trioxide aggregate on different strains of Candida albicans in vitro. J Conserv Dent. 2014;17(3):276-9.

39. Ohshima T, Ikawa S, Kitano K, Maeda N. A Proposal of 
Remedies for Oral Diseases Caused by Candida: A Mini Review. Front Microbiol. 2018;9:1522.

40. Karale R, Odedra KM, Srirekha A, Champa C, Shetty A, Pushpalatha S, Sharma R. Effect of dentin on the antimicrobial efficacy of $3 \%$ sodium hypochlorite, $2 \%$ chlorhexidine, $17 \%$ ethylenediaminetetraacetic acid, and $18 \%$ etidronic acid on Candida albicans: An in vitro study. J Conserv Dent 2016;19(5):455-60.

41. Noites R, Pina-Vaz C, Rocha R, Carvalho MF, Gonçalves A, Pina-Vaz I. Synergistic antimicrobial action of chlorhexidine and ozone in endodontic treatment. Biomed Res Int 2014;2014:592423.

42. Kermeoglu F, Aksoy U, Kalender A, Oztan MD, Oguz EI, Kiyan M. Determination of the Minimum Inhibitory Concentrations of Alexidine and Chlorhexidine Against Enterococcus faecalis and Candida albicans: An In Vitro Study. Cureus 2018;10(2):e2221.

43. Bohora A, Kokate S. Evaluation of the Role of Probiotics in Endodontic Treatment: A Preliminary Study. J Int Soc Prev Community Dent 2017;7(1):46-51.

44. Weckwerth PH, Carnietto C, Weckwerth AC, Duarte MA, Kuga MC, Vivan RR. In vitro susceptibility of oral Candida albicans strains to different $\mathrm{pH}$ levels and calcium hydroxide saturated aqueous solution. Braz Dent J. 2012;23(3):192-8.

45. Ahangari Z, Mojtahed Bidabadi M, Asnaashari M, Rahmati A, Tabatabaei FS. Comparison of the Antimicrobial Efficacy of Calcium Hydroxide and Photodynamic Therapy Against Enterococcus faecalis and Candida albicans in Teeth With Periapical Lesions; An In Vivo Study. J Lasers Med Sci. 2017;8(2):72-78.

46. Jose J, Krishnamma S, Peedikayil F, Aman S, Tomy N, Mariodan JP. Comparative Evaluation of Antimicrobial Activity of QMiX, 2.5\% Sodium Hypochlorite, 2\% Chlorhexidine, Guava Leaf Extract and Aloevera Extract Against Enterococcus faecalis and Candida albicans An in-vitro Study. J Clin Diagn Res 2016;10(5):ZC20-3.

47. De Miranda RG, Gusman HD, Colombo AP. Antimicrobial efficacy of the EndoVac system plus PDT against intracanal Candida albicans: an ex vivo study. Braz Oral Res 2015;29(1):S1806-83242015000100308.

48. Monajemzadeh A, Ahmadi Asoor S, Aslani S, SadeghiNejad B. In vitro antimicrobial effect of different root canal sealers against oral pathogens. Curr Med Mycol 2017;3(2):7-12. 